\title{
Measuring Tremor - Does Recording Time Matter?
}

\section{Gunilla Wastensson ${ }^{1 *}$, Eva M Andersson ${ }^{1}$ and Rita Bast-Pettersen ${ }^{2}$}

${ }^{1}$ Department of Occupational and Environmental Medicine, Sahlgrenska University Hospital and University of Gothenburg, Box 414, SE-405 30 Gothenburg, Sweden ${ }^{2}$ National Institute of Occupational Health, P.O. Box 8149 Depot, N-0033 Oslo, Norway

\begin{abstract}
Objective: The CATSYS Tremor Pen has been used in several studies for measurement of tremor among workers with occupational exposure to neurotoxins like mercury and manganese. The main purpose of this study was to investigate whether recording time has an impact on the measured tremor characteristics. Other aims were to investigate whether there are interactions between recording time and age, and between recording time and (selfreported) nicotine use, respectively; to assess the test-retest repeatability of the instrument; to investigate a possible practice effect when performing the test repeatedly; and to evaluate agreement with another tremor test.
\end{abstract}

Methods: The participants ( $n=44)$ consisted of former shipyard workers (mean age 67 years, range 59-76 years). Postural hand tremor was evaluated using the CATSYS Tremor Pen. Five tremor recordings were made; the first lasted $16.4 \mathrm{~s}$, the next three lasted $8.2 \mathrm{~s}$ each and the fifth lasted $65.6 \mathrm{~s}$.

Results: There was a significant association between recording time and harmonic index; longer recording time produced higher harmonic index. There was no effect of nicotine use or age that was consistent over all recording times, and no practice effect was seen. The agreement with another tremor test was moderate to good, as was the test-retest reliability.

Conclusion: Some of the tremor characteristics are affected by length of recording time and hence care should be taken when comparing results across studies or with follow-up. The results indicate that the use of a recording time longer than $16.4 \mathrm{~s}$ seems to be of doubtful value.

Keywords: CATSYS; Tremor; Neurotoxic effect; Recording time; Accelerometer; Practice effect

\section{Introduction}

Tremor is defined as "any involuntary, approximately rhythmic and roughly sinusoidal movement of a body part". It is produced by alternating or synchronous contractions of antagonist muscles [1]. It is characterized by its frequency, which is the number of cycles per second $(\mathrm{Hz})$ and by its amplitude. The frequency of the mechanical component of tremor is largely determined by the inertia and stiffness of the body part, therefore the frequency of tremor is different for different body parts [2]. For example, hand tremor has a frequency of 6-8 $\mathrm{Hz}$ [3]; elbow tremor has a frequency of 3-4 Hz [3] or 3-5 Hz [2], while the shoulder joint has a frequency of $0.5-2 \mathrm{~Hz}$ [3]. Tremor frequency slowly decreases with age [4] but amplitude is not necessarily affected. A slight, barely visible physiologic tremor appears normally in all humans [4] and may be enhanced in the presence of factors such as fatigue, anxiety or certain medical conditions. Nicotine exposure also increases the amplitude of physiologic tremor [1]. Exposure to several neurotoxins has been reported to cause tremor, including neurotoxic metals such as mercury [5] and manganese [6].

Measurement of tremor can be used to evaluate early adverse effects on the central nervous system among workers with occupational exposure to neurotoxic metals. Improvement in hygiene conditions has successively reduced workplace exposure, and effects are consequently expected to be smaller; hence, more sensitive tests are demanded. Quantitative methods for tremor assessment have been introduced over several years, including hole tremormeters and lightweight accelerometers. When using these methods for evaluating the effects of neurotoxic metals on tremor, it must be remembered that the results can be affected by factors such as anatomical location of the recording, duration of recording, and type of transducers used [7]. For example, a hole tremormeter such as the Static Steadiness Test [8] measures displacement amplitude, whereas an accelerometer uses acceleration data. Moreover, tremor naturally fluctuates over time, and so one of the major problems in measuring tremor is to obtain a representative sample. Different researchers do not necessarily use the same recording time and number of trials, which may contribute to discrepancies in results [7]. A very short recording time may be insufficient to elicit tremor, and thus the recording time needs to be prolonged or trials repeated. The use of a longer recording time may generate fatigue, which in turn may provoke tremor that is not obvious in normal conditions. Repeated tremor measurements may give a more representative sample, but apart from raising questions concerning the test-retest repeatability of the test, repeated administration of an instrument may create a practice effect; that is, better performance with more trials. Although practice effects are widely known, the literature offers little guidance on their interpretation and handling.

The CATSYS Tremor Pen [9] is a portable lightweight microaccelerometer that has been used in several studies for evaluation of tremor among groups of workers with occupational exposure to mercury vapour [10-13] and manganese [14-22]. The equipment has been validated and standardized [23,24]. The use of the tremor pen requires little effort, as the task is simply to hold the pen without

*Corresponding author: Gunilla Wastensson, Department of Occupational and Environmental Medicine, Sahlgrenska University Hospital and University of Gothenburg, Box 414, SE-405 30 Gothenburg, Sweden, Tel: +46 31786 2894; Fax: +46 3182 5004; E-mail: gunilla.wastensson@amm.gu.se

Received July 30, 2016; Accepted October 20, 2016; Published October 27, 2016

Citation: Wastensson G, Andersson EM, Bast-Pettersen R (2016) Measuring Tremor - Does Recording Time Matter? J Neurol Neurophysiol 7: 398. doi:10.4172/2155-9562.1000398

Copyright: ( $) 2016$ Wastensson G, et al. This is an open-access article distributed under the terms of the Creative Commons Attribution License, which permits unrestricted use, distribution, and reproduction in any medium, provided the original author and source are credited. 
performing any other tasks and no speeded component is included. However, the default recording time ( $8.2 \mathrm{~s})$ set by the CATSYS system has been considered to be too short and a longer testing time has been recommended [8]. There is still a lack of general agreement among researchers regarding the most appropriate recording time and number of trials. Moreover, the question of whether repeated exposure to this kind of tremor test is subject to a significant practice effect has not been settled.

The purpose of this study was to investigate whether recording time has an impact on tremor characteristics. Specific aims were to investigate i) whether the expected tremor characteristics are independent of recording time $(8,16$ or $65 \mathrm{~s})$, ii) whether there is an overall effect of age or nicotine use on tremor characteristics independent of recording time, iii) whether there are interactions between recording time on the one hand, and age or nicotine use respectively, iv) whether there is any practice effect as a result of being exposed to the same tremor test repeatedly, and v) the repeatability of the CATSYS Tremor Pen test. We also wanted to evaluate agreement between tremor characteristics measured using the CATSYS Tremor Pen and those from the Static Steadiness Test.

\section{Material and Methods}

\section{Study participants}

The study group consisted of 44 former shipyard workers. The participants were all male, and had previously worked as ship welders, filers or electricians at the same shipyards in the southwestern part of Sweden. Each participant completed a questionnaire about previous and current diseases, medication, and current alcohol and tobacco consumption in terms of the use of smoked tobacco or smokeless tobacco in the form of moist snuff [25]. Additional information concerning each participant's state of health was collected via a brief interview and a clinical examination, conducted by a physician

\begin{tabular}{|c|c|c|c|c|c|}
\hline & \multirow[b]{2}{*}{$\begin{array}{c}\text { All } \\
(n=44)\end{array}$} & \multicolumn{2}{|c|}{ Age } & \multicolumn{2}{|c|}{ Nicotine use } \\
\hline & & $\begin{array}{c}\text { Under } 65 \\
(n=21)\end{array}$ & $\begin{array}{c}\text { Over } 65 \\
(n=23)\end{array}$ & $\begin{array}{l}\text { Users } \\
(n=9)\end{array}$ & $\begin{array}{c}\text { Non-users } \\
(n=35)\end{array}$ \\
\hline $\begin{array}{l}\text { Mean age } \\
\text { (range) }\end{array}$ & $\begin{array}{c}67.2 \\
(59-76)\end{array}$ & $\begin{array}{c}62.1 \\
(59-65)\end{array}$ & $\begin{array}{c}72.0 \\
(66-76)\end{array}$ & $\begin{array}{c}64.7 \\
(59-76)\end{array}$ & $\begin{array}{c}67.9 \\
(59-76)\end{array}$ \\
\hline $\begin{array}{c}\text { Mean BMI } \\
\text { (range) }\end{array}$ & $\begin{array}{c}26.5 \\
(20.1-44.8)\end{array}$ & $\begin{array}{c}27.2 \\
(20.7-44.8)\end{array}$ & $\begin{array}{c}25.9 \\
(20.1-32.4)\end{array}$ & $\begin{array}{c}24.3 \\
(20.7-26.3)\end{array}$ & $\begin{array}{c}27.1 \\
(20.1-44.8)\end{array}$ \\
\hline $\begin{array}{c}\text { Current } \\
\text { smokers (n) }\end{array}$ & $14 \%(6)$ & $24 \%(5)$ & $4 \%(1)$ & $67 \%(6)$ & $0 \%(0)$ \\
\hline $\begin{array}{l}\text { Current nicotine } \\
\text { users (n) }\end{array}$ & $20 \%(9)$ & $33 \%(7)$ & $9 \%(2)$ & $100 \%(9)$ & $0 \%(0)$ \\
\hline $\begin{array}{c}\text { Alcohol } \\
\text { consumption }{ }^{1} \\
\text { (g/week) }\end{array}$ & $\begin{array}{c}65.0 \\
(0-268)\end{array}$ & $\begin{array}{c}87.4 \\
(2-268)\end{array}$ & $\begin{array}{c}44.5 \\
(0-225)\end{array}$ & $\begin{array}{c}72.7 \\
(3-268)\end{array}$ & $\begin{array}{c}62.9 \\
(0-225)\end{array}$ \\
\hline $\begin{array}{c}\text { Use of } \\
\text { medication }\end{array}$ & $45 \%(20)$ & $38 \%(8)$ & $52 \%(12)$ & $56 \%(5)$ & $43 \%(15)$ \\
\hline
\end{tabular}

Table 1: Background characteristics of the study participants $(n=44)$.

('Self-reported)
$(G W)$. The participants were essentially healthy subjects in the upper middle-age or older, and none of the participants had a history or clinical signs of any neurologic disease. Forty-five percent of the participants reported use of medication prescribed by a physician, such as drugs for hypertension, hypercholesterolemia, or diabetes mellitus; none of these drugs were known to cause tremor. The background characteristics of the 44 study participants are given in Table 1. The study was approved by the Ethics Committee of the University of Gothenburg, and all participants gave their written informed consent.

\section{Tremor tests}

CATSYS tremor pen: The CATSYS equipment consists of a data logger which is connected with a serial cable to a portable PC. The data logger records data from four sensors including the CATSYS Tremor Pen, which consists of a biaxial micro-accelerometer embedded in a low-mass stylus $(12 \mathrm{~cm} \times 0.8 \mathrm{~cm})$. Tremor is recorded in a frequency band varying from $0.9 \mathrm{~Hz}$ to $15 \mathrm{~Hz}$. Tremor was recorded according to the standard procedure described in the manual [9] and in another paper [23]. The participant is asked to sit down in a chair and hold the stylus as one would hold an ordinary pen with the elbow bent at an angle of $90^{\circ}$ and free of body contact or other obstacles. The stylus is held horizontally, parallel to the abdomen at approximately $10 \mathrm{~cm}$ in front of the navel. The participant is asked to look at the tip of the stylus and to breathe normally during recording. Tremor registrations are displayed in real time on a time axis plot on the computer screen. The combined signal from the two perpendicular accelerometers is transformed by the system's software using fast Fourier transformation. Four measures calculated by the CATSYS software were used in the present study: Tremor Intensity, Center Frequency, Frequency Dispersion and Harmonic Index (Table 2).

Static steadiness test: The Kløve-Matthews Static Steadiness Test is a stylus and hole apparatus [8]. The participant sits in a chair without an armrest and is not allowed to support their arm on the desk. The task is to hold a stylus within each of nine successively smaller holes for $15 \mathrm{~s}$ without it touching the sides. The cumulative number of and duration of contacts between stylus and base plate are recorded.

\section{Test procedures}

The tremor tests were performed immediately after the clinical evaluation and were conducted by the same investigator (GW). The participants were requested to wear prescription glasses if necessary and not to smoke or use wet snuff during the $60 \mathrm{~min}$ before testing began. The tremor tests were administered in the same order to all study participants; first the Static Steadiness Test and then the CATSYS Tremor Pen. The Static Steadiness Test was administered once. For the CATSYS Tremor Pen, five tremor recordings were made for each hand; the first lasted $16.4 \mathrm{~s}$, the next three each lasted $8.2 \mathrm{~s}$ and the fifth lasted $65.5 \mathrm{~s}$. The $8.2 \mathrm{~s}$ recording was made three times in order to investigate whether repeated use of the CATSYS Tremor Pen could

\begin{tabular}{|l|l|}
\hline Characteristics & Definitions \\
\hline Tremor Intensity $\left(\mathrm{m} / \mathrm{s}^{2}\right)$ & Root mean square of accelerations recorded in the $0.9-15 \mathrm{~Hz}$ band. Larger values indicate more tremors. \\
\hline Center Frequency $(\mathrm{Hz})$ & $\begin{array}{l}\text { Mean frequency of accelerations in the } 0.9-15 \mathrm{~Hz} \text { band: } 50 \% \text { of the area under the spectrum is at frequencies above the center frequency } \\
\text { and } 50 \% \text { is below. }\end{array}$ \\
\hline Frequency Dispersion $(\mathrm{Hz})$ & $\begin{array}{l}\text { Standard deviation }(\mathrm{SD}) \text { of the center frequency, indicating the degree of irregularity of the tremor; } 68 \% \text { of the power is dissipated within the } \\
\text { center frequency } \pm \text { SD. A regular tremor has small frequency dispersion, indicating that most of the area is within a narrow frequency band. }\end{array}$ \\
\hline Harmonic Index & $\begin{array}{l}\text { This index compares the tremor frequency pattern with the pattern of a single harmonic oscillation, which has an } \mathrm{HI} \text { of } 1.00 . \text { The HI decreases } \\
\text { when the tremor is composed of many oscillations. }\end{array}$ \\
\hline
\end{tabular}

Table 2: Measures used to characterize postural arm tremor recorded with the CATSYS Tremor pen.

('Definitions of characteristics from Danish Product Development (2000)) 
lead to improved results related to a potential practice effect. The reason for applying the longer $65.5 \mathrm{~s}$ recording was to add a feature of fatigue in the test, which might elicit tremor that is not obvious in normal conditions. The five recordings are hereafter denoted $16,8_{(1)}$, $8_{(2)}, 8_{(3)}$ and 65 .

\section{Statistics}

Repeated recordings on the same individual are likely to be positively correlated and cannot be considered independent. When investigating the effect of recording time, order of the recordings, and practice effect, the following mixed model was used:

$$
\mathrm{yij}=\beta_{0}+\mathrm{b}_{\mathrm{i}}+\beta_{1}{ }^{*} \mathrm{t}_{1}+\beta_{2}{ }^{*} \mathrm{t}_{2}+\ldots+\beta_{\mathrm{p}}{ }^{*} \mathrm{t}_{\mathrm{p}}+\mathrm{e}_{\mathrm{ij}} \text {, }
$$

where $y_{i j}=$ CATSYS tremor outcome for participant $i$ and recording $j$ and $b_{i}$ and $e_{i j}$ are stochastic effects which are assumed to be independent of each other with variances $\sigma^{2} b$ and $\sigma^{2} e$, respectively. The variables $t_{1}, \ldots, t_{p}$ are indicator variables (value 0 or 1 ). In the analysis of the effect of the length of recording time $(8,16$ or $65 \mathrm{~s})$, the two indicator variables $t_{1}$ and $t_{2}$ represent the recording times $16 \mathrm{~s}$ and $65 \mathrm{~s}\left(8_{(1)}\right.$ was set as the reference); significance indicates that the outcome differed depending on recording time. In the analysis of the effect of order, the four indicator variables $t_{1}, t_{2}, t_{3}$ and $t_{4}$ represent the recordings $8_{(1)}, 8_{(2)}$, $8_{(3)}$ and 65 , with the first recording, $16 \mathrm{~s}$, being set as the reference. In the analysis of practice effect, $\mathrm{t}_{1}$ and $\mathrm{t}_{2}$ represent the recordings $8_{(2)}$ and $8_{(3)}$, and here $8_{(1)}$ was set as the reference. The F-test in PROC MIXED in SAS was used in the analyses.

Correlation (Spearman rank) between the CATSYS tremor outcome and recording time length was calculated for each participant and used in a Wilcoxon test. A high absolute value of the average correlation indicates a trend. A corresponding analysis was made to test for a possible trend in order of recordings.

A test of a general age effect was made using the following model:

$$
\mathrm{yij}=\beta_{0}+\mathrm{b}_{\mathrm{i}}+\beta_{1}{ }^{*} \mathrm{t}_{1}+\beta_{2}{ }^{*} \mathrm{t}_{2}+\beta_{\mathrm{gr}}{ }^{*} \mathrm{Group}+\mathrm{e}_{\mathrm{ij}} \text {, }
$$

where $y_{i j}, b_{i}$ and $e_{i j}$ are defined as above, Group refers to age group (up to 65 or older than 65), and $t_{1}$ and $t_{2}$ represent the $16 \mathrm{~s}$ and $65 \mathrm{~s}$ recording times ( 8 , was the reference). A significant effect of Group indicates a general age effect. A corresponding test was performed with Group representing nicotine users versus non-users. We also investigated whether there was a significant interaction between Group and recording time, using the following model and the F-test in PROC MIXED in SAS:

$$
\mathrm{y}_{\mathrm{ij}}=\beta_{0}+\mathrm{b}_{\mathrm{i}}+\beta_{1}{ }^{*} \mathrm{t}_{1}+\beta_{2}{ }^{*} \mathrm{t}_{2}+\beta_{\mathrm{gr}}{ }^{\star} \text { Group }+\beta_{1-} \mathrm{G}^{*} \mathrm{t}_{1}{ }^{*} \mathrm{Group}+\beta_{2 \_} \mathrm{G}^{*}{ }_{2}{ }^{\star} \text { Group }+\mathrm{e}_{\mathrm{ij}}
$$

For Group=age group, "no interaction" means that the difference in tremor between the age groups is the same at all three recording times, and the difference between recording times is the same among younger and older participants. Conversely, a significant interaction indicates that the differences between the age groups are not the same at different recording times, or that the differences between recording times are not the same for both age groups. A corresponding analysis was made for Group=nicotine use. If there was a significant interaction between Group and recording time, the pairwise differences were tested for significance (LSMEANS in PROC MIXED) using the BonferroniHolm procedure for multiple testing [26].

Associations between the outcome variables from the Static Steadiness Test and the tremor characteristics from the CATSYS tremor pen were assessed using Spearman rank correlation.

Repeatability was assessed using the intra-class correlation (ICC) estimated from the within-subject variance and the between-subject variance $\left(\sigma_{\mathrm{b}}^{2} /\left(\sigma_{\mathrm{b}}^{2}+\sigma_{\mathrm{e}}^{2}\right)\right.$, the coefficient of variation $100\left(\mathrm{si} / \bar{y}_{i}\right)$ based on the individual standard deviation and mean, and the standard error of measurement (SEM) estimated from the within-subject variance. In addition, pairwise comparisons were made using equivalence tests and confidence intervals for the difference.

\section{Results}

\section{Effect of recording time}

The four tremor characteristics calculated by the CATSYS Tremor Pen were analyzed using three different recording times $\left(8_{(1)} \mathrm{s}, 16\right.$ $\mathrm{s}$ and $65 \mathrm{~s})$ in all study participants $(\mathrm{n}=44)$. The mean values for the outcome variables in the dominant hand are shown in Table 3 and the distribution is shown in Figure 1.

We investigated if there was a trend related to recording time for each of the four measures derived from the recordings with the CATSYS Tremor Pen (Table 3). Harmonic Index (HI) was significantly related to recording time $(\mathrm{p}<0.0001)$ and the association was monotonic; higher values of HI were related to longer recording times $(p<0.0001)$. A significant association with recording time was also found for Center Frequency $(\mathrm{p}=0.03)$, but further analysis showed no clear monotonic trend. For Frequency Dispersion, the association was not statistically significant $(\mathrm{p}=0.08)$. No association was found between Tremor Intensity and recording time.

\section{Effect of recording time in relation to age and nicotine use}

We investigated whether there was a general effect of age (up to 65 years vs. older than 65 ) on tremor as assessed with the CATSYS Tremor Pen; for example, if the older men had higher Tremor Intensity independent of the length of the recording time. Since there were a higher percentage of nicotine users among the younger men, we performed the analysis on the non-users to avoid confounding between age effect and nicotine effect. A corresponding analysis was made regarding a possible general effect of nicotine, using only men up to 65 years of age. Not for any of the four measures (Tremor Intensity, Center Frequency, Frequency Dispersion, and Harmonic Index), did we find a general difference due to age that was consistent over all three recording times ( $p$-values between 0.45 and 0.85 , F-test in a mixed model, data not shown). We also found no general difference due to nicotine use

\begin{tabular}{|c|c|c|c|c|}
\hline Recording time & Tremor Intensity $\left(\mathrm{m} / \mathrm{s}^{2}\right)$ & Center Frequency $\left(\mathrm{Hz}\right.$ or $\left.\mathbf{s}^{-1}\right)$ & Frequency Dispersion $(\mathrm{Hz})$ & Harmonic Index \\
\hline $8_{(1)}$ Mean (SD) & $0.132(0.061)$ & $7.18(0.96)$ & $3.02(0.90)$ & $0.90(0.05)$ \\
\hline 16 Mean (SD) & $0.137(0.060)$ & $6.90(1.10)$ & $2.82(0.85)$ & $0.92(0.04)$ \\
\hline 65 Mean (SD) & $0.134(0.058)$ & $7.04(0.88)$ & $2.89(0.82)$ & $0.95(0.02)$ \\
\hline Association with recording time? ${ }^{1}$ & No $(p=0.72)$ & Yes $(p=0.03)$ & Borderline $(p=0.08)$ & Yes $(p<0.0001)$ \\
\hline Monotonic trend? ${ }^{2}$ & No $(p=0.95)$ mean $\left(r_{s}\right)=0.02$ & Borderline $(p=0.06)$ mean $\left(r_{s}\right)=-0.18$ & No $(p=0.14)$ mean $\left(r_{s}\right)=-0.14$ & Yes $(p<0.0001)$ mean $\left(r_{s}\right)=0.52$ \\
\hline
\end{tabular}
that was present at all recording times (p-values between 0.11 and 0.94 , for F-test in a mixed model, data not shown).

Table 3: Mean and standard deviation of tremor recordings using the CATSYS Tremor Pen at different recording times ( $n=44$ participants).

( ${ }^{1}$ Test of difference in tremor for different recording time, using a mixed model and an F-test; ${ }^{2}$ The individual rS-values (Spearman correlation) are used in a Wilcoxon test 

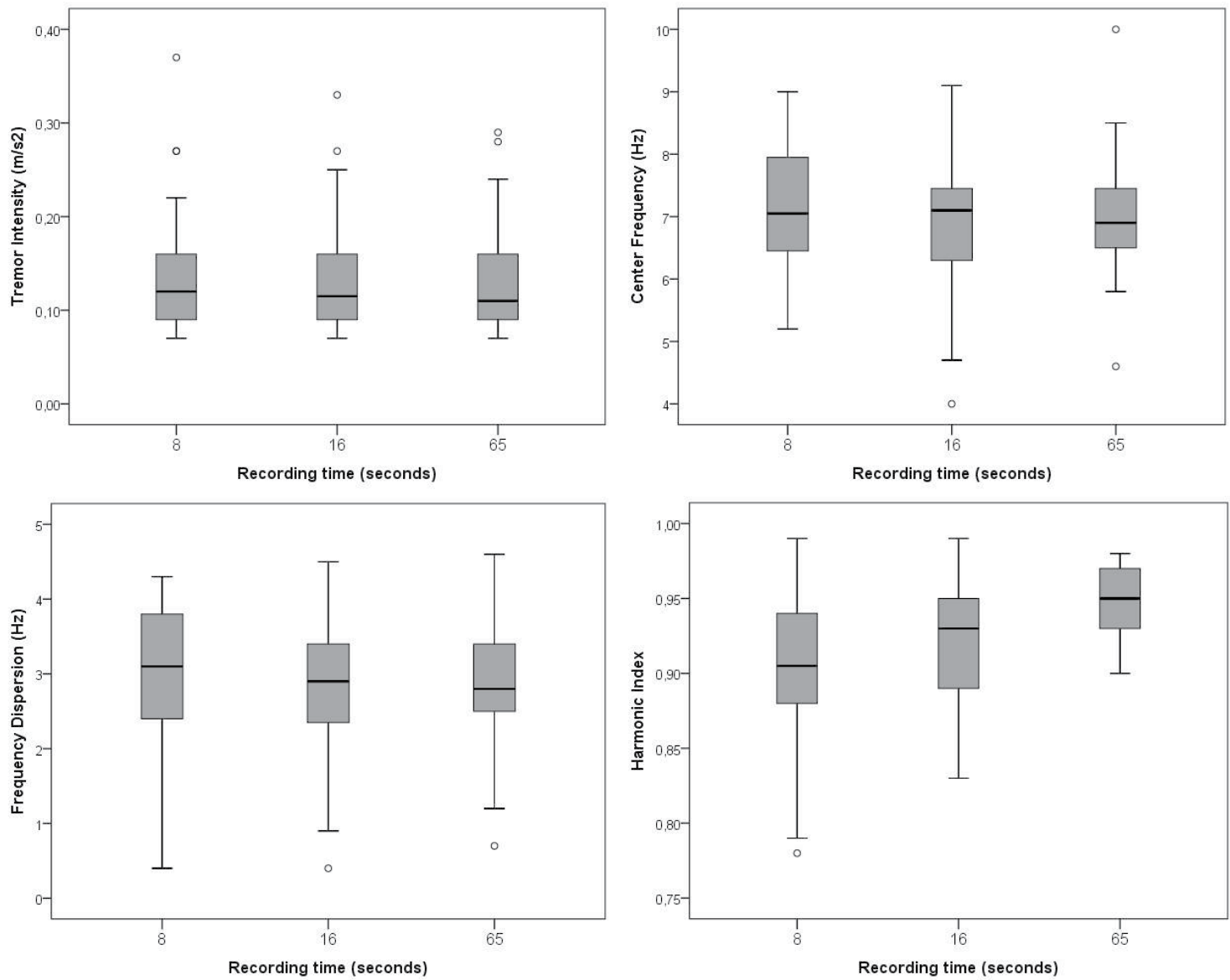

Figure 1: Boxplots showing the distribution of the four tremor measures at different recording times: 8,16 and $65 \mathrm{~s}$ ( $\mathrm{n}=44$ participants). The box shows the quartiles and the circles represent outliers (values beyond $1.5^{\star}$ (q3-q1) from q1 and q3, respectively).

\section{Possible interaction between age and recording time}

No significant interaction was found between recording time and age regarding Tremor Intensity, Frequency Dispersion and Harmonic Index (p-values 0.36, 0.11 and 0.31). For Center Frequency, there was a significant interaction between age and recording time $(\mathrm{p}=0.02)$; the difference in Center Frequency between recording times was not the same for both age groups. The older participants had lower Center Frequency when measuring over $16 \mathrm{~s}$ compared to $8 \mathrm{~s}$ (means 6.69 and 7.25 , $\left.\mathrm{p}_{\mathrm{adiBH}}<0.01\right)$ and when measuring over 16 seconds compared to 65 seconds (means 6.69 and $7.19, \mathrm{p}_{\mathrm{adiBH}}<0.01$ ). and when measuring over 16 seconds compared to 65 seconds (means 6.69 and 7.19 , padjBH $<0.01$ ). There was no significant effect of recording time among the younger participants.

\section{Possible interaction between nicotine use and recording time}

We also investigated whether there was a significant interaction between nicotine use and recording time. No significant interaction was found for any of the four measures from the CATSYS Tremor Pen ( $\mathrm{p}$-values $0.62,0.92,0.16$ and 0.15 ).

\section{Practice effects}

We investigated if there was a relation to order of the recording, when the recording time was held constant, using the three $8 \mathrm{~s}$ recording sessions. A significant association with recording order was found for Tremor Intensity $(\mathrm{p}=0.03)$. Further analysis revealed indications of a monotonic trend in the opposite direction than expected (average correlation $0.23, \mathrm{p}=0.03$ ). The participants tended to have worse performance in the last trial compared to the first two (Figure 2) and hence no practice effect was found.

We also examined the results from the tremor recordings in relation to order of all recordings, irrespective of recording time $\left(16,8_{(1)}, 8_{(2)}, 8_{(3)}\right.$ and 65). Significant associations with recording order were found for Center Frequency $(p=0.0008)$ and Harmonic Index $(p<0.0001)$. Further analysis revealed no monotonic trend for Center Frequency. The test for a monotonic trend was significant for $\mathrm{HI}(\mathrm{p}=0.006)$. However, further investigation showed that the lowest values were all recorded for the three $8 \mathrm{~s}$ recordings, followed by the first recording $(16 \mathrm{~s})$; the $65 \mathrm{~s}$ recording had the highest value for HI (Figure 2). This indicates that the association was with recording time, as shown in Table 3 and not with order of recording.

\section{Reliability of the CATSYS tremor pen}

The test-retest reliability of the CATSYS instrument was evaluated over repeated $8 \mathrm{~s}$ recordings, both two and three trials, respectively. For the $3 \times 8 \mathrm{~s}$ recording, the ICC was highest for Tremor Intensity (0.91) and lowest for Harmonic Index (0.45) (Table 4). The individual coefficient of variation (CV) had an average of $10 \%$ or less for Tremor Intensity, Center Frequency and Harmonic Index. The standard error of measurement (SEM) had a similar pattern, with highest value for Frequency Dispersion. For all four CATSYS measures, the repeatability was better for two trials $\left(8_{(1)}\right.$ and $\left.8_{(2)}\right)$ compared to three trials. For Tremor Intensity, there was a significant difference between $8_{(3)}$ and the 
Citation: Wastensson G, Andersson EM, Bast-Pettersen R (2016) Measuring Tremor - Does Recording Time Matter? J Neurol Neurophysiol 7: 398. doi:10.4172/2155-9562.1000398
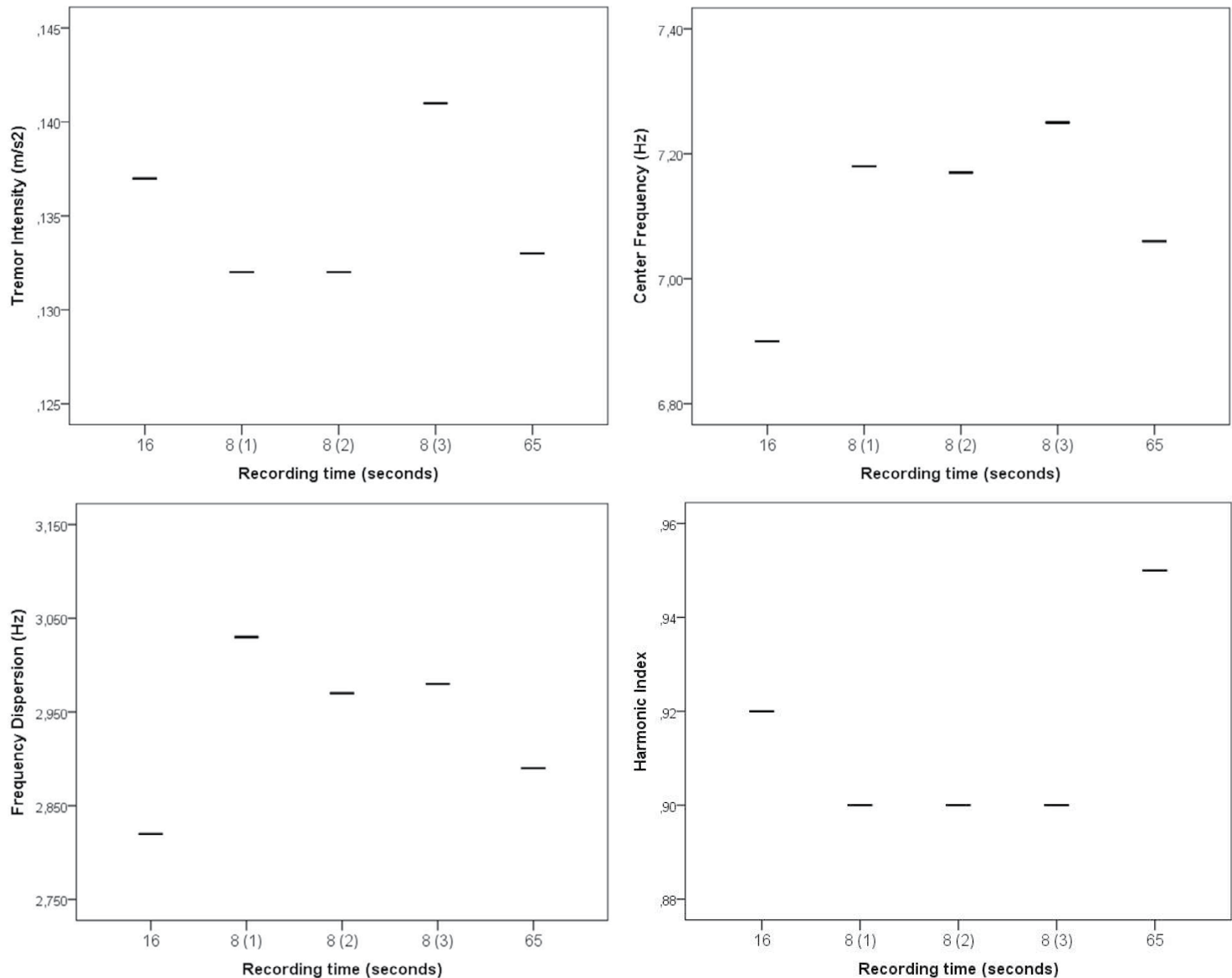

Figure 2: Mean values for CATSYS tremor pen recordings of four tremor characteristics, in the order that the recordings were made ( $\mathrm{n}=44$ participants).

\begin{tabular}{|c|c|c|c|c|c|}
\hline & & Tremor Intensity & Center Frequency & Frequency Dispersion & Harmonic Index \\
\hline \multirow[t]{5}{*}{$8_{(1)}, 8_{(2)}, 8_{(3)}$} & ICC & 0.91 & 0.80 & 0.78 & 0.45 \\
\hline & $\begin{array}{c}\text { CV } 1 \\
\text { (mean, p5, p95) }\end{array}$ & $10(0,16)$ & $5(1,12)$ & $14(4,34)$ & $3(1,7)$ \\
\hline & SEM $^{2}$ (SEM\%) & $0.019(14 \%)$ & $0.45(6 \%)$ & $0.43(14 \%)$ & $0.036(4 \%)$ \\
\hline & $\begin{array}{l}\text { Between-individual variance } \\
(95 \% \mathrm{Cl})\end{array}$ & $0.0033(0.0022-0.0054)$ & $0.79(0.52-1.32)$ & $0.64(0.42-1.09)$ & $0.0010(0.0006-0.0021)$ \\
\hline & $\begin{array}{l}\text { Within-individual variance } \\
(95 \% \mathrm{Cl})\end{array}$ & $0.00034(0.00026-0.00047)$ & $0.20(0.15-0.27)$ & $0.18(0.14-0.25)$ & $0.0013(0.0010-0.0018)$ \\
\hline \multirow[t]{5}{*}{$8_{(1)}, 8_{(2)}$} & $\operatorname{ICC}\left(\mathrm{rP}^{3}\right)$ & $0.95(0.95)$ & $0.84(0.845)$ & $0.82(0.81)$ & $0.66(0.67)$ \\
\hline & $\begin{array}{c}\mathrm{CV}^{1} \\
\text { (mean, p5, p95) }\end{array}$ & $7(0,15)$ & $4(0,11)$ & $11(2,28)$ & $2(0,6)$ \\
\hline & SEM $^{2}$ (SEM\%) & $0.013(10 \%)$ & $0.39(5 \%)$ & $0.39(13 \%)$ & $0.029(3 \%)$ \\
\hline & $\begin{array}{l}\text { Between-individual variance } \\
(95 \% \mathrm{Cl})\end{array}$ & $0.0031(0.0021-0.0051)$ & $0.81(0.53-1.37)$ & $0.66(0.43-1.13)$ & $0.0017(0.0010-0.0031)$ \\
\hline & $\begin{array}{l}\text { Within-individual variance } \\
(95 \% \mathrm{Cl})\end{array}$ & $0.0002(0.0001-0.0003)$ & $0.16(0.11-0.25)$ & $0.15(0.10-0.24)$ & $0.0008(0.0006-0.0013)$ \\
\hline
\end{tabular}

Table 4: Reliability measures for the three $8 \mathrm{~s}$ recordings; intra-class correlation, coefficient of variation, standard error of measurement and between- and within-subject variance ( $n=44$ participants).

('The distribution of the individual coefficients of variation (mean, $5^{\text {th }}$ and $95^{\text {th }}$ percentile). ${ }^{2}$ Estimated using the within-individual variance and the intercept in the mixed model. ${ }^{3}$ Pearson correlation coefficient)

other two recordings, where equivalence could not be shown (p-values for equivalence tests above 0.10 , data not shown).

\section{Comparison between CATSYS Tremor Pen and Static Steadiness Test}

We compared the results from the tremor recordings using the
CATSYS Tremor Pen with those from the Static Steadiness Test performed on the same participant $(n=43)$. The correlation (Spearman, $r_{s}$ ) between Tremor Intensity as measured by the CATSYS Tremor Pen and the Static Steadiness Test was highest for the 16 second recording (Figure 3), both for number of contacts where $r_{s=} 0.56$ (range: $0.47-0.50$ for the other recording times) and duration of contacts where $r_{s=} 0.65$ 

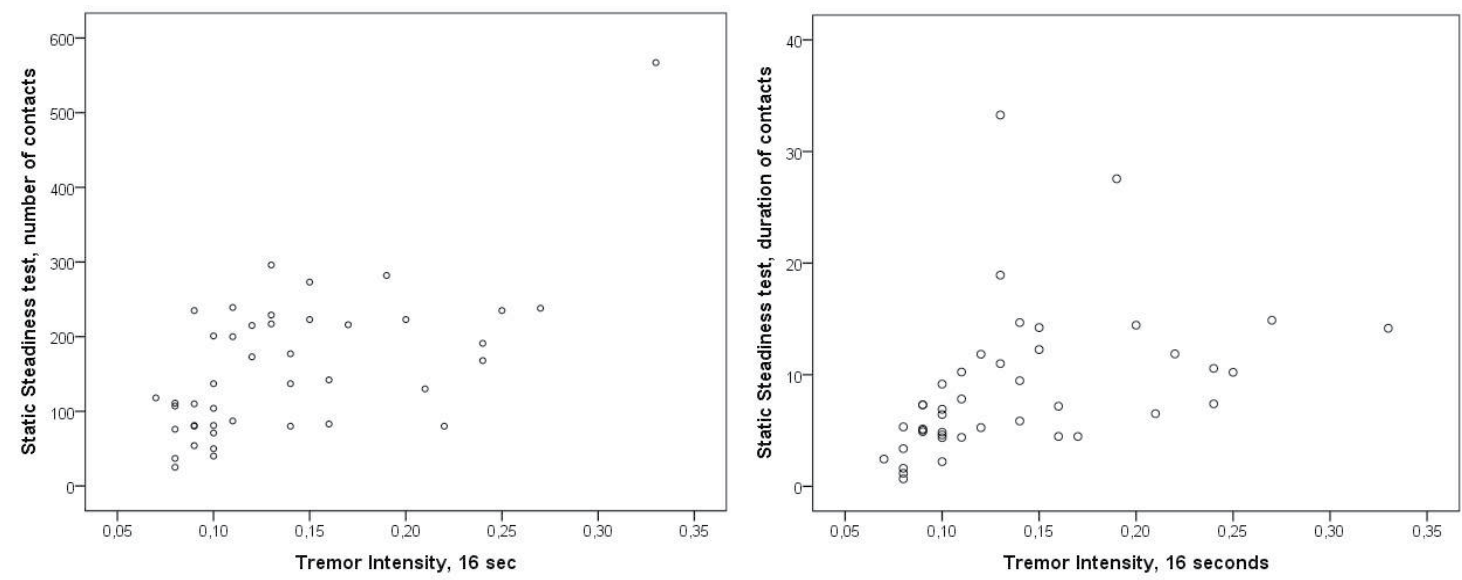

Figure 3: Tremor intensity (16 s recording) vs. static steadiness test; number of contacts (left) and duration of contacts (right), n=43 participants.

(range: $0.57-0.62$ for the other recording times). For the other tremor characteristics derived from the CATSYS Tremor Pen, there were only weak associations with the Static Steadiness Test $\left(\mathrm{r}_{\mathrm{s}} \leq 0.29\right)$.

\section{Discussion}

\section{Summary of results}

The main finding was a significant association between recording time and Harmonic Index, with longer recording time producing higher values of HI. We found no effect of nicotine use that was consistent over all recording times, and no consistent effect of age in the studied age segment (59-76 years). No practice effect could be shown for the CATSYS Tremor Pen and the test-retest reliability for the instrument was moderate to good. The agreement between Tremor Intensity and another tremor test (Static Steadiness Test) was moderate to good; the strongest association was found at the $16 \mathrm{~s}$ recording session.

\section{Recording time}

The default recording time ( $8.2 \mathrm{~s})$ set by the CATSYS system has been considered to be too short, and a longer testing time has been recommended $[8,24]$. Thus, some studies have applied the tremor test with a longer recording time of $16.4 \mathrm{~s}$ [22,27-29] or even 24.6 $\mathrm{s}$ [24]. However, in most cases the test was administered only once. In a study by Wastensson et al. [13], the test was administered three times for $8.2 \mathrm{~s}$ each time and the median time was used for statistical calculations. In the present study, each participant was measured five times for tremor, using the CATSYS Tremor pen: over $16.4 \mathrm{~s}$, over 8.2 $\mathrm{s}$ (repeated three times), and finally over $65.6 \mathrm{~s}$. Such a long recording period could add a feature of fatigue to the test, which might provoke tremor that is not obvious in normal conditions. On the other hand, a longer recording time might provide a more precise tremor assessment. Except for Harmonic Index, no significant associations were found between recording time and the tremor characteristics derived from recordings with the CATSYS Tremor Pen. To our knowledge, this is the first study comparing three different recording times using the CATSYS Tremor Pen.

\section{Recording time and harmonic index}

The finding that the Harmonic Index increased with recording time, with the highest value at the $65 \mathrm{~s}$ recording, is of special interest. The HI has been used in several studies for evaluating possible adverse effects of neurotoxic agents, but in most cases without significant effects associated with this measure [13,18,20-22]. Bowler et al. [16] reported impaired results in $\mathrm{HI}$ among manganese-exposed welders, but the values indicate that the results were for a measure other than the HI. In a study by Papapetropoulos et al. [30] increased HI was found among patients with Parkinson's disease in an $8.2 \mathrm{~s}$ session when the participants were instructed to hold their hand in a relaxed position (rest tremor). Other studies have omitted this measure [14] because it has been suggested to be unreliable in test-retest experiments [31].

The Harmonic Index is defined as an index that compares the tremor frequency pattern with the pattern of a single harmonic oscillation (which has $\mathrm{HI}=1.00$ ) and a value close to 1 should indicate that the tremor consists of a few dominating frequencies compared to the spectrally broader physiological tremor [23,31]. The association between recording time and $\mathrm{HI}$ found in the present study might be due to how this variable is calculated by the system's software: a rectangle of area $\mathrm{R}$ is formed to enclose the highest peak in the interval $0.9-15 \mathrm{~Hz}$, the area under the curve (AUC) is calculated and the $\mathrm{HI}$ is calculated as $1-A U C / R$. Thus if there is only one high peak, $R$ will be very large in relation to AUC (AUC/R close to zero) and then HI will be close to 1, as pointed out by Edwards and Beuter [23]. It is likely that the probability of getting at least one very high peak increases with recording time, thus increasing the probability of a high HI value (close to 1). Other measures of harmonicity which have been suggested instead of $\mathrm{HI}$ are the center of mass of the sorted spectrum, $\mathrm{Hcm}$, and a transformed $\mathrm{HI}$ [31]. This suggested transformation $\left(\mathrm{HI}^{*}=-\log (1-\mathrm{HI})\right)$ was used in the study by Wastensson et al. [13].

\section{Recording time and nicotine use}

Exposure to nicotine is mainly via cigarette smoking, but the use of wet snuff is not uncommon in Sweden [25]. Experimental studies have demonstrated that exposure to cigarette smoke induces an increase in postural tremor amplitude [32-34]. Smoking habits have been pointed out as an important potential confounder in epidemiological studies which investigate the effect on tremor [35]. Some occupational studies have reported effects of smoking habits on tremor characteristics such as smaller Frequency Dispersion [10,14,27,35]. Regarding Center Frequency, studies have reported varying results; lower Center Frequency among smokers [13,36], no effect on Center Frequency $[10,14,35]$ or even higher Center Frequency among smokers [27]. We found no nicotine effect on any of the tremor characteristics, probably because the participants were asked not to smoke or use wet snuff before examination. Moreover, in the present study, nicotine users were few. 


\section{Recording time and age}

Desprès et al. [24] reported that Center Frequency and Frequency Dispersion decreased with age and Edlund et al. [27] found that Harmonic Index increased and Frequency Dispersion decreased with age. One reason for the lack of significant associations between tremor characteristics and age in the present study could be that almost all participants were middle-aged or older (59-76 years); conversely, the participants in the study by Després et al. [24] had an age span from 20 to 70 years. However, we did find an interaction between age and recording time in the present study; Center Frequency was significantly lower when measuring over $16 \mathrm{~s}$, compared to 8 or $65 \mathrm{~s}$, but only among older participants.

\section{Practice effects}

Practice effects refer to the impact on performance of repeated exposure to a test $[37,38]$. In general, the neuropsychological tests most susceptible to the effects of practice are those with a speeded component, those requiring an infrequently practiced response and those with a single, easily conceptualized solution [37,38]. Practice effects tend to be most pronounced with repetition of the same test, but general test-taking exposure alone can also improve subsequent performances [38].

Most studies of practice effects in psychological/neurobehavioral testing have focused on cognitive tests in the form of intelligence tests [38] a broader battery of neuropsychological tests [39] or scholastic aptitude tests used to gain admission to higher education [40].

Indications of a practice effect have been reported in many studies using intelligence tests [38]. One study found improved test results after repeated testing with a one-year interval among age groups up to 75 years in tests for verbal learning and memory and in tests for attention/concentration [39]. Bast-Pettersen et al. [41] found improved intelligence test scores (WAIS subtests) in a twelve year follow-up, which might have been due to a practice effect.

Most studies including tremor tests have administered the test once, with an $8.2 \mathrm{~s}$ presentation $[8,18,20,23]$. In a study by Cleeves and Findley [42], tremor was recorded with an accelerometer every hour for $6 \mathrm{~h}$ in one group of untreated patients with essential tremor and on five to seven occasions separated for at least one week in another group of essential tremor patients; a significant trend towards lower amplitude was found in the long-term assessment group. To our knowledge, this is the first study examining the potential practice effect from repeated presentation of the same tremor test among relatively healthy participants without neurological diseases.

One way to test a possible practice effect would be to administer the same test with the same recording time several times. The finding that the participants tended to have higher Tremor Intensity (worse performance) in the last of three $8.2 \mathrm{~s}$ sessions compared to the first two indicates that there was no practice effect.

The use of the tremor pen requires little effort, as the task is simply to hold the pen without performing any other tasks, and no speeded component is included. In a study of repeatability of grip strength and manual dexterity based on weekly testing over three weeks, participants improved their results in the test for dexterity, which has a speeded component, but not in the test for grip strength [43]. This could indicate that a manual test is more likely to be subject to the practice effects if the test has a speeded component.

\section{Reliability}

Several measures were used to assess repeatability. A high ICC indicates that the within-subject variation is small, compared to the total variation. Atkinson and Nevill [44] have categorized an ICC above 0.90 as "high", and by this categorization, only Tremor Intensity had a high ICC, which could indicate good reproducibility. Further, our finding that the ICC was low for the HI supports the finding reported in the study by Edwards and Beuter [23], where the Pearson correlation between two repeats was low, 0.26 . ICC is a relative measure of reliability, and will decrease as the between-subject variability increases. $\mathrm{CV}$ and SEM are both functions of the within-subject variation, and are not affected by the between-subject variation. Furthermore, SEM is an absolute index, given in the same unit as the measurements and quantifying the precision of individual scores on a test [45]. For Tremor Intensity, Center Frequency, and Harmonic Index, the individual standard deviation was on average at most $10 \%$ of the individual mean. ICC, CV and SEM in combination indicate that the repeatability is moderate to good for Tremor Intensity and Center Frequency. Our results show that the repeatability is better for the $2 \times 8$ s recording session than $3 \times 8 \mathrm{~s}$ recording session. To our knowledge, this is the first study that has evaluated the test-retest reliability of the CATSYS Tremor Pen using ICC, SEM and CV.

\section{Comparison between CATSYS tremor pen and static steadiness test}

In the present study, the agreement between Static Steadiness Test and the CATSYS Tremor Pen was investigated, using different recording times. We found a moderate to good correlation between Tremor Intensity, as measured by the CATSYS Tremor Pen and number and duration of contacts, respectively, measured by the Static Steadiness Test; the strongest association was found for the $16 \mathrm{~s}$ recording session. There are several explanations why the agreement is not perfect such as the time delay between the tests. A high association was shown between different tremor variables derived from the CATSYS Tremor Pen and a laser-based system when a simultaneous recording was performed [23], but the systems produced different results when the recordings were not simultaneous [13,23]. Furthermore, Static Steadiness Test measures displacement amplitude, whereas an accelerometer uses acceleration data. Finally, hand posture and duration of tests may also be of importance.

\section{Limitations}

The number of participants in the present study was quite low. The participants were men of middle age or older, which makes it difficult to generalize the results to younger age-groups and women. When taking into consideration that the test does not require neither speed nor strength, functions where gender differences are well-known, the reliability of the test is not expected to differ between men and women. The number of nicotine users was few, limiting the possibilities to evaluate any effects of nicotine use on tremor.

\section{Conclusion}

We found that some of the tremor characteristics are affected by length of recording time, such as the Harmonic Index. The CATSYS Tremor Pen is well suited to measuring tremor in occupational settings, but care should be taken when comparing results across studies or with follow-up. Our results indicate that the use of a recording time longer than $16.4 \mathrm{~s}$ seems to be of doubtful value. 


\section{Acknowledgement}

The authors would like to thank the participants in this study and Gunne Garsell for skilful administrative assistance. Financial support for this study was partly provided by the Swedish Council for Working Life and Social Research.

\section{References}

1. Elble R, Koller W (1990) Tremor. John Hopkins University Press, Baltimore USA.

2. Elble RJ (1996) Central mechanisms of tremor. J Clin Neurophysiol 13: 133-144.

3. Deuschl G, Raethjen J, Lindemann M, Krack P (2001) The pathophysiology of tremor. Muscle Nerve 24: 716-735.

4. Deuschl G, Krack P, Lauk M, Timmer J (1996) Clinical neurophysiology of tremor. J Clin Neurophysiol 13: 110-121.

5. Berlin M, Zalups R, Fowler B (2007) Mercury. In: Handbook on the Toxicology of Metals. Nordberg G, Fowler B, Nordberg M, L. Friberg (edtrs) Academic Press Inc., Burlington, USA.

6. Calne DB, Chu NS, Huang CC, Lu CS, Olanow W (1994) Manganism and idiopathic parkinsonism: Similarities and differences. Neurology 44: 1583-1586.

7. Beuter A and de Geoffroy A (1996) Can tremor be used to measure the effects of chronic mercury exposure in human subjects? Neurotoxicology17: 213-228.

8. Bast-Pettersen R, Ellingsen DG (2005) The Kløve-Matthews static steadiness test compared with the DPD TREMOR. Comparison of a fine motor contro task with measures of tremor in smokers and manganese-exposed workers. Neurotoxicology 26: 331-342.

9. Danish Product Development (2000) CATSYS 2000 user's manual. Snekkersten, Denmark: Danish Product Development Ltd.

10. Bast-Pettersen R, Ellingsen DG, Efskind J, Jordskogen R, Thomassen $Y(2005)$ A neurobehavioral study of chloralkali workers after the cessation of exposure to mercury vapor. Neurotoxicology 26: 427-437.

11. Echeverria D, Aposhian HV, Woods JS, Heyer NJ, Aposhian MM, et al. (1998) Neurobehavioral effects from exposure to dental amalgam $\mathrm{Hg}(\mathrm{o})$ : New distinctions between recent exposure and $\mathrm{Hg}$ body burden. FASEB J 12: 971-980.

12. Lucchini R, Cortesi I, Facco P, Benedetti L, Camerino D, et al. (2002) Neurotoxic effect of exposure to low doses of mercury. Med Lav 93: 202-214.

13. Wastensson G, Lamoureux D, Sällsten G, Beuter A, Barregård L (2006) Quantitative tremor assessment in workers with current low exposure to mercury vapor. Neurotoxicol Teratol 28: 681-693.

14. Bast-Pettersen R, Ellingsen DG, Hetland SM, Thomassen Y (2004) Neuropsychological function in manganese alloy plant workers. Int Arch Occup Environ Health 77: 277-287.

15. Blond M and Netterstrom B (2007) Neuromotor function in a cohort of Danish steel workers. NeuroToxicology 28: 336-344

16. Bowler RM, Roels HA, Nakagawa S, Drezgic M, Diamond E, et al. (2007) Dose-effect relationships between manganese exposure and neurological neuropsychological and pulmonary function in confined space bridge welders. Occup Environ Med 64: 167-177.

17. Chang Y, Kim Y, Woo S, Song H, Kim S, et al. (2009) High signal intensity on magnetic resonance imaging is a better predictor of neurobehaviora performances than blood manganese in asymptomatic welders. Neurotoxicology 30: 555-563.

18. Ellingsen DG, Konstantinov R, Bast-Pettersen R, Merkurjeva L, Chashchin M, et al. (2008) A neurobehavioral study of current and former welders exposed to manganese. Neurotoxicology 29: 48-59.

19. Harari R, Harari F, Gerhardsson L, Lundh T, Skerfving S, et al. (2012) Exposure and toxic effects of elemental mercury in gold-mining activities in Ecuador. Toxicol Lett 213: 75-82.

20. Lucchini R, Apostoli P, Perrone C, Placidi D, Albini E, et al. (1999) Long-term exposure to "low levels" of manganese oxides and neurofunctional changes in ferroalloy workers. Neurotoxicology 20: 287-297.

21. Sanchez-Ramos J, Reimer D, Zesiewicz T, Sullivan K, Nausieda PA (2011) Quantitative analysis of tremors in welders. Int J Environ Res Public Health 8: 1478-1490.
2. Wastensson G, Sallsten G, Bast-Pettersen R, Barregard L (2012) Neuromoto function in ship welders after cessation of manganese exposure. Int Arch Occup Environ Health 85: 703-713

23. Edwards R, Beuter A (1997) Sensitivity and specificity of a portable system measuring postural tremor. Neurotoxicol Teratol 19: 95-104.

24. Després C, Lamoureux D, Beuter A (2000) Standardization of a neuromotor test battery: The CATSYS system. Neurotoxicology 21: 725-735.

25. Hugoson A, Hellqvist L, Rolandsson M, Birkhed D (2012) Dental caries in relation to smoking and the use of Swedish snus: Epidemiological studies covering 20 years (1983-2003). Acta Odontol Scand 70: 289-296.

26. Holm S (1979) A simple sequentially rejective multiple test procedure. Scandinavian journal of statistics 6: 65-70.

27. Edlund M, Burström L, Hagberg M, Lundström R, Nilsson T, et al. (2015) Quantitatively measured tremor in hand-arm vibration-exposed workers. In Arch Occup Environ Health 88: 305-310.

28. Ellingsen DG, Kusraeva Z, Bast-Pettersen R, Zibarev E, Chashchin M, et al. (2014) The interaction between manganese exposure and alcohol on neurobehavioral outcomes in welders. Neurotoxicol Teratol 41: 8-15.

29. Bast-Pettersen R, Ulvestad B, Færden K, Clemm T, Olsen R, et al (2016) Tremor and hand-arm vibration syndrome (HAVS) in road maintenance workers. Int Arch Occup Environ Health. doi:10.1007/s00420-016-1175-x

30. Papapetropoulos S, Katzen H, Scanlon B, Guevara A, Singer C, et al. (2010) Objective quantification of neuromotor symptoms in Parkinson's disease: Implementation of a portable, computerized measurement tool. Parkinson's Disease.

31. Edwards R, Beuter A (1999) Indexes for identification of abnormal tremor using computer tremor evaluation systems. IEEE Trans Biomed Eng 46: 895-898.

32. Lippold OC, Williams EJ, Wilson CG (1980) Finger tremor and cigarette smoking. Br J Clin Pharmacol 10: 83-86.

33. Maykoski KA, Rubin MB, Day AC (1976) Effect of cigarette smoking on postural muscle tremor. Nurs Res 25: 39-43.

34. Shiffman SM, Gritz ER, Maltese J, Lee MA, Schneider NG, et al. (1983) Effects of cigarette smoking and oral nicotine on hand tremor. Clin Pharmacol Ther 33: $800-805$.

35. Ellingsen DG, Bast-Pettersen R, Efskind J, Gjølstad M, Olsen R, et al. (2006) Hand tremor related to smoking habits and the consumption of caffeine in male industrial workers. Neurotoxicology 27: 525-533.

36. Beuter A, Edwards R (1999) Using frequency domain characteristics to discriminate physiologic and parkinsonian tremors. J Clin Neurophysiol 16 484-494

37. Lezak M, Howieson D, Bigler E, Tranel D (2012) Neuropsychological assessment. Oxford University Press Inc., New York, USA

38. McCaffrey R, Duff K, Westerwelt H (2000) Practitioner's Guide to Evaluating Change with intellectual assessment instruments. Kluwer Academic/Plenum Publishers, New York, USA.

39. Mitrushina M, Satz P (1991) Effect of repeated administration of a neuropsychological battery in the elderly. J Clin Psychol 47: 790-801.

40. Hausknecht JP, Halpert JA, Di Paolo NT, Moriarty Gerrard MO (2007) Retesting in selection: A meta-analysis of coaching and practice effects for tests of cognitive ability. J Appl Psychol 92: 373-385.

41. Bast-Pettersen R, Skare $\varnothing$, Nordby KC, Skogstad M (2015) A twelve-yea longitudinal study of neuropsychological function in non-saturation professional divers. Int Arch Occup Environ Health 88: 669-682

42. Cleeves L, Findley LJ (1987) Variability in amplitude of untreated essentia tremor. J Neurol Neurosurg Psychiatry 50: 704-708.

43. Haward BM, Griffin MJ (2002) Repeatability of grip strength and dexterity tests and the effects of age and gender. Int Arch Occup Environ Health 75: 111-119.

44. Atkinson G, Nevill AM (1998) Statistical methods for assessing measuremen error (reliability) in variables relevant to sports medicine. Sports Med 26 : 217-238.

45. Weir J (2005) Quantifying test-retest reliability using the intraclass correlation coefficient and the SEM. J Strength Conditioning Res 19: 231-240. 